\title{
Individual isotoxic radiation dose escalation based on V20 and advanced technologies benefits unresectable stage III non-small cell lung cancer patients treated with concurrent chemoradiotherapy: Iong term follow-up
}

\author{
Ming Liu ${ }^{1,2, *}$, Zhongtang Wang ${ }^{2, *}$, Tao Zhou ${ }^{2}$, Antang Zhou ${ }^{3}$, Qian Zhao ${ }^{2}$, Hongsheng \\ $\mathrm{Li}^{2}$, Hongfu Sun ${ }^{2}$, Wei Huang ${ }^{2}$ and BaoSheng $\mathrm{Li}^{2,4}$ \\ ${ }^{1}$ School of Medicine and Life Sciences, University of Jinan-Shandong Academy of Medical Sciences, Jinan, Shandong, P.R. \\ China \\ ${ }^{2}$ Department of Radiation Oncology, Shandong Cancer Hospital Affiliated to Shandong University, Shandong Academy of \\ Medical Sciences, Jinan, Shandong, P.R. China \\ ${ }^{3}$ Department of General Surgery, Yanggu People's Hospital, Liaocheng, Shandong, P.R. China \\ ${ }^{4}$ Engineering Research Center for Medical Imaging and Radiation Therapy of Shandong Province, Jinan, Shandong, P.R. \\ China \\ * These authors have contributed equally to this study and should be considered as co-first authors
}

Correspondence to: BaoSheng Li, email: baoshli1963@163.com

Keywords: non-small cell lung cancer, chemoradiotherapy, lung V20, Individual isotoxic dose escalation, advanced radiotherapy technologies

Received: September 30, $2016 \quad$ Accepted: March 09, $2017 \quad$ Published: March 16, 2017

Copyright: Liu et al. This is an open-access article distributed under the terms of the Creative Commons Attribution License 3.0 (CC BY 3.0), which permits unrestricted use, distribution, and reproduction in any medium, provided the original author and source are credited.

\section{ABSTRACT}

Under the assumption that the highest therapeutic ratio could be achieved by increasing the total tumor dose (TTD) to the limits of normal tissues, the phase I trial was conducted in patients with unresectable stage III non-small cell lung cancer treated with concurrent chemoradiotherapy, to determine the feasibility and effects of individual isotoxic radiation dose escalation based on bilateral lung V20 and advanced technologies. Consecutive eligible patients were assigned to cohorts of eight. V20 of each cohort was increased from $27 \%$ to $30 \%, 33 \%, 35 \%, 37 \%$, and so on. The criterion for cessation of dose escalation was defined as $\geq 2$ patients in each cohort experienced dose limiting toxicity. Isotoxic dose escalation was based on V20, functional imaging was used to improve the accuracy of radiotherapy. To test the power of escalation dose, patients with TTD over $66 \mathrm{~Gy}$ were assigned to the higher dose group (HD), while the others to the standard dose one (SD). In result, the recommended value of $\mathrm{V} 20$ was 35\%. For all patients, follow-up ranged from 1 to 112 months, median overall and progression free survivals were 25.0 and $\mathbf{1 3 . 0}$ months, respectively. The 1-, 3-, 5- and 8-year overall survival (OS) rates were $72.5 \%, 22.5 \%$, $17.5 \%$, and $10.0 \%$, respectively. Especially, the OS and local recurrence-free survival of patients in HD group were significantly longer than those in SD one $(P=0.035$, $\mathbf{P}=\mathbf{0 . 0 0 7}$, respectively) without increasing severe toxicity. Thus, individual isotoxic dose escalation based on V20 with advanced technologies was feasible and effective.

\section{INTRODUCTION}

Non-small cell lung cancer (NSCLC) remains one of the most common and fatal malignancies, and approximately $35 \%$ of patients with NSCLC present with locally advanced disease [1]. Concurrent chemoradiotherapy (CCRT) has been established as the standard care for unresectable locally advanced NSCLC
(LANSCLC), however, the prognosis is still unsatisfactory $[2,3]$. Radiation dose escalation has been shown to be able to improve local control and overall survival (OS) of patients with LANSCLC in several studies [49]. However, the Radiation Therapy Oncology Group (RTOG) 0617 trial indicated that higher radiation dose of 74 Gy did not produce an OS benefit compared with the standard dose of $60 \mathrm{~Gy}$, and the most possible explanation 
of this result might be the greater toxicity on the normal tissue [10]. Thus, the safety and efficacy of radiation dose escalation in the setting of CCRT for LANSCLC remains uncertain, and personalised isotoxic radiation dose escalation ensuring the safety of the organs at risk (OARs) may be a potential solution [11-12].

Lots of studies on radiotherapy for patients with LANSCLC focused on new radiation approaches. Modern advanced techniques such as 18F-fluorodeoxyglucose positron emission tomography/computed tomography (18F-FDG PET-CT) and intensity-modulated radiation therapy (IMRT) have substantially enhanced the accuracy of the radiotherapy delivery through improved target conformality [13-15]. The identification of functional lung using lung perfusion information obtained from singlephoton emission computed tomography (SPECT), coupled with IMRT had the potential to reduce the pulmonary toxicity [16-21]. Shrinking field during treatment course might be feasible to spare more normal tissues [22]. Accelerated and hyperfractionated radiotherapy schedules resulting in reduced overall treatment time and less tumor repopulation have been shown to improve outcomes in LANSCLC compared to conventional fractionation [2324]. These approaches, either alone or in combination, could enable radiation dose escalation without increasing the risk of toxicity, and help to improve local-regional control and OS in LANSCLC.

In addition, bilateral lung V20 (volume of the whole lung receiving $\geq 20 \mathrm{~Gy}$ ) is one of the most important predictors for radiation-induced lung toxicity and has been commonly used as a constraint for dose escalation. Thus, in this study, we investigated the feasibility and effects of individual isotoxic radiation dose escalation in patients with unresectable stage III NSCLC treated with CCRT based on V20, SPECT, 18F-FDG PET-CT, and late-course accelerated hyperfractionated (LCAHF) IMRT.

\section{RESULTS}

\section{Patient characteristics}

Thirty-seven males and three females were enrolled, with a median age of 62 years (range, from 34 to 72 years). The patient characteristics were presented in Table 1. Stage distribution was as following: IIIa $42.5 \%$ ( $n=$ 17), IIIb $57.5 \%(n=23)$. Most patients had squamous carcinoma $(60.0 \%)$. No perfusion defects were observed in 3 patients $(7.5 \%)$, while grade 1 perfusion defects were observed in 13 patients $(32.5 \%)$, grade 2 in 15 patients $(37.5 \%)$, and grade 3 in 9 patients $(22.5 \%)$. All patients completed the study protocol treatment, however, 3 patients' treatments were suspended for 7 to 14 days because of severe hematological toxicity.

\section{Radiotherapy dose escalation and maximum tolerated value}

The first and second cohorts (8 patients each) were treated with a mean radiotherapy dose of 62.2 (95\% CI, 59.8-64.6 Gy) and 62.9 Gy (95\% CI, 57.9-67.8 Gy), respectively. None of these patients had radiation pneumonitis (RTP) or radiation esophagitis (RTE). In the third and fourth cohorts, mean radiotherapy doses were 63.6 (95\% CI, 57.5-69.7 Gy) and 68.3 Gy (95\% CI, 60.9-75.6 Gy), respectively, and each cohort had

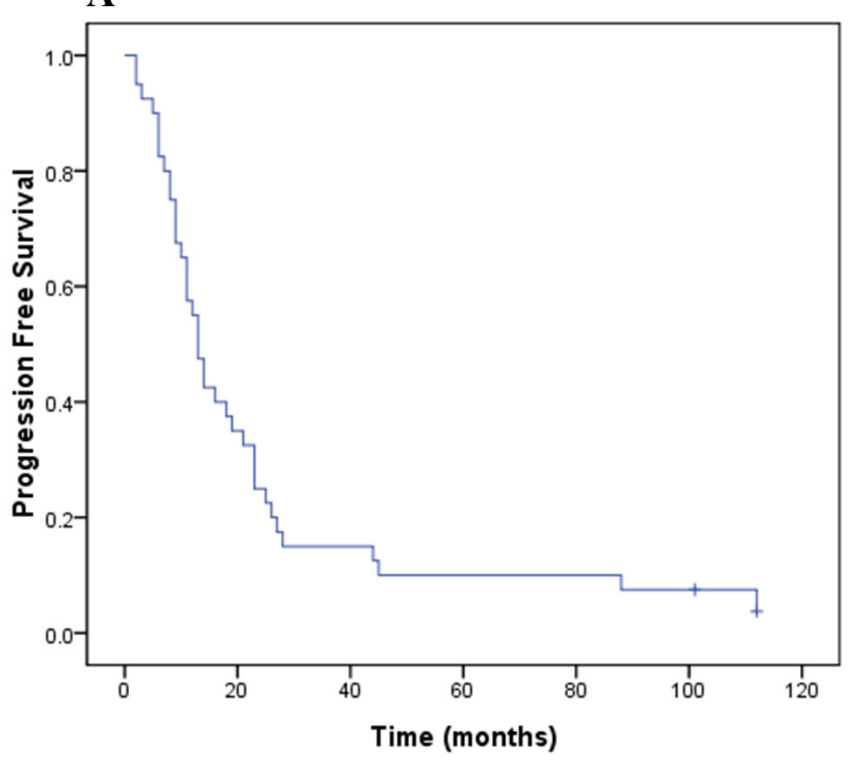

\section{B}

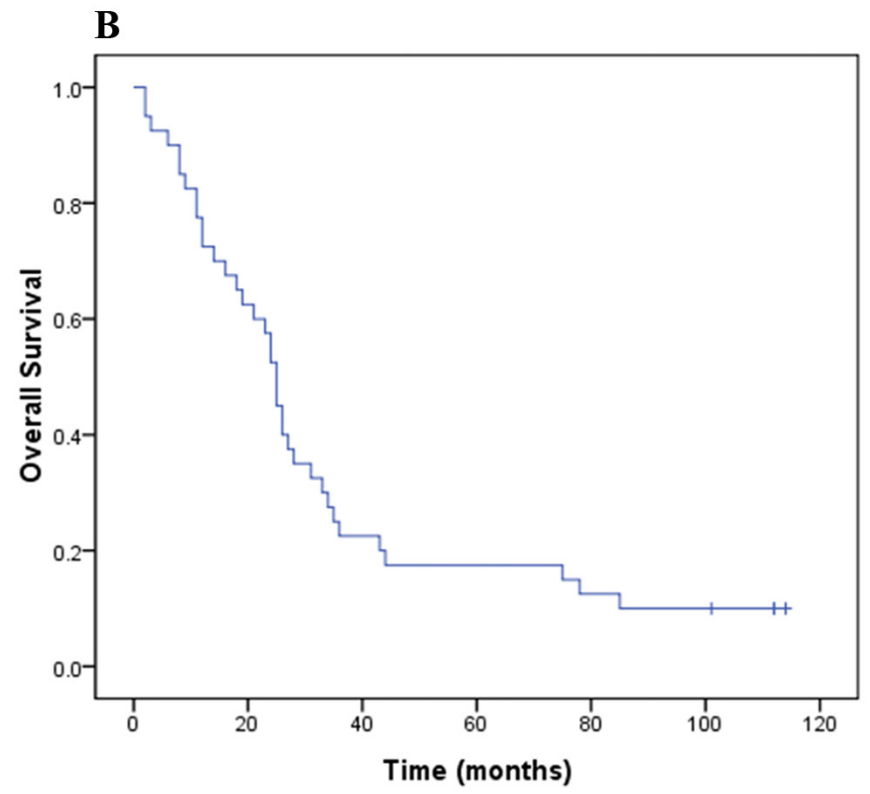

Figure 1: PFS in months for all patients (A), and OS for all patients (B). 
Table 1: Patient characteristics in this phase I study

\begin{tabular}{|c|c|c|c|c|c|}
\hline Characteristics & Cohort 1 & Cohort 2 & Cohort 3 & Cohort 4 & Cohort 5 \\
\hline \multirow{3}{*}{$\begin{array}{l}\text { Gender, n (\%) } \\
\text { Male } \\
\text { Female }\end{array}$} & & & & & \\
\hline & $7(87.5)$ & $7(87.5)$ & $8(100)$ & $7(87.5)$ & $8(100)$ \\
\hline & $1(12.5)$ & $1(12.5)$ & $0(0)$ & $1(12.5)$ & $0(0)$ \\
\hline $\begin{array}{l}\text { Age (years), } \\
\text { Median (range) }\end{array}$ & $66(43-71)$ & $56(40-71)$ & $57(34-72)$ & $61(51-72)$ & $62(48-71)$ \\
\hline \multirow{4}{*}{$\begin{array}{l}\text { Histolgy, } \mathrm{n}(\%) \\
\text { Squamous carcinoma } \\
\text { Adenocarcinoma } \\
\text { Large cell carcinoma }\end{array}$} & & & & & \\
\hline & $6(75.0)$ & $7(87.5)$ & $5(50.0)$ & $2(25.0)$ & $4(50.0)$ \\
\hline & $2(25.0)$ & $1(12.5)$ & $2(12.5)$ & $4(50.0)$ & $1(12.5)$ \\
\hline & $0(0)$ & $0(0)$ & $1(37.5)$ & $2(25.0)$ & $3(37.5)$ \\
\hline \multicolumn{6}{|l|}{ Stage, n (\%) } \\
\hline IIIa & $7(87.5)$ & $3(37.5)$ & $3(37.5)$ & $2(25.0)$ & $2(25.0)$ \\
\hline IIIb & $1(12.5)$ & $5(62.5)$ & $5(62.5)$ & $6(75.0)$ & $6(75.0)$ \\
\hline \multirow{4}{*}{$\begin{array}{l}\text { Tumor localization, n (\%) } \\
\text { Upper lobes } \\
\text { Lower lobes } \\
\text { Hilar areas }\end{array}$} & & & & & \\
\hline & $4(50.0)$ & $5(62.5)$ & $4(50.0)$ & $4(50.0)$ & $3(37.5)$ \\
\hline & $3(37.5)$ & $2(25.0)$ & $2(25.0)$ & $2(25.0)$ & $2(25.0)$ \\
\hline & $1(12.5)$ & $1(12.5)$ & $2(25.0)$ & $2(25.0)$ & $3(37.5)$ \\
\hline \multirow{3}{*}{$\begin{array}{l}\text { Performance status, } \mathrm{n}(\%) \\
0 \\
1\end{array}$} & & & & & \\
\hline & $5(62.5)$ & $1(12.5)$ & $3(37.5)$ & $4(50.0)$ & $4(50.0)$ \\
\hline & $3(37.5)$ & $7(87.5)$ & $5(62.5)$ & $4(50.0)$ & $4(50.0)$ \\
\hline \multirow{5}{*}{$\begin{array}{l}\text { Perfusion deficit grade, } \mathrm{n}(\%) \\
0 \\
1 \\
2 \\
3\end{array}$} & & & & & \\
\hline & $0(0)$ & $1(12.5)$ & $1(12.5)$ & $1(12.5)$ & $0(0)$ \\
\hline & $1(12.5)$ & $3(37.5)$ & $3(37.5)$ & $3(37.5)$ & $3(37.5)$ \\
\hline & $3(37.5)$ & $3(37.5)$ & $3(37.5)$ & $2(25.0)$ & $4(50.0)$ \\
\hline & $4(50.0)$ & $1(12.5)$ & $1(12.5)$ & $2(25.0)$ & $1(12.5)$ \\
\hline \multicolumn{6}{|l|}{ Total tumor dose, $\mathrm{n}(\%)$} \\
\hline$\leq 66 \mathrm{~Gy}$ & $5(62.5)$ & $4(50.0)$ & $7(87.5)$ & $1(12.5)$ & $2(25.0)$ \\
\hline$>66$ Gy & $3(37.5)$ & $4(50.0)$ & $1(12.5)$ & $7(87.5)$ & $6(75.0)$ \\
\hline
\end{tabular}

Abbreviations: $\mathrm{n}=$ number.

A

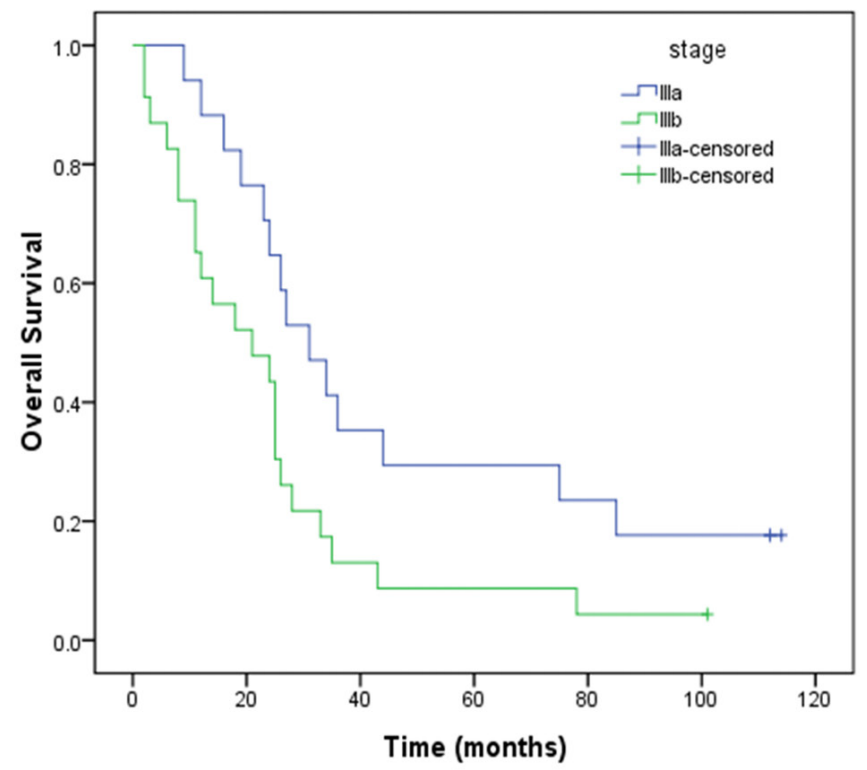

B

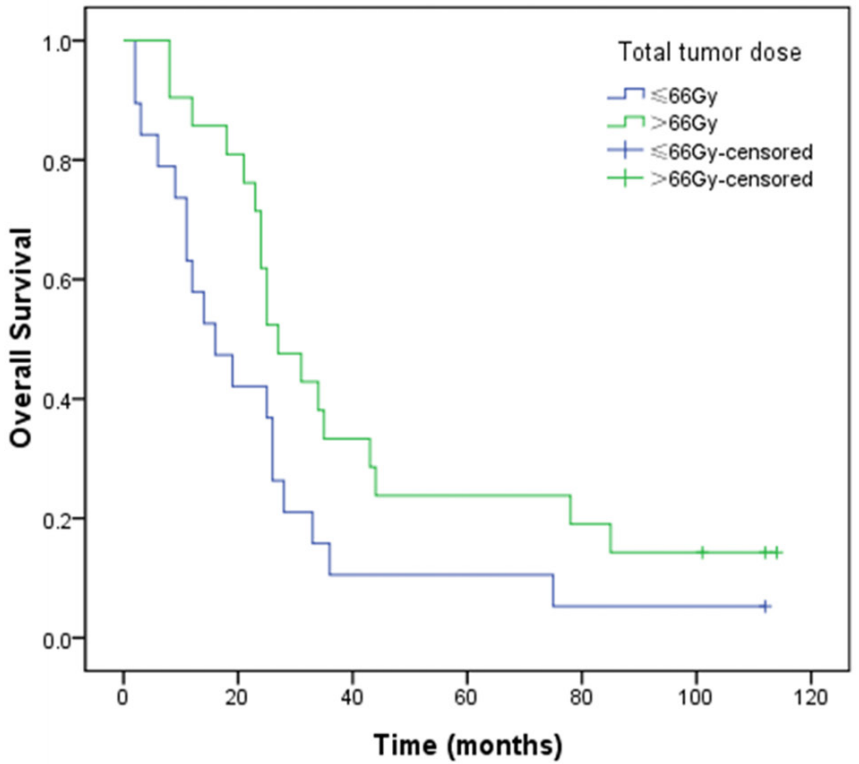

Figure 2: Kaplan-Meier OS curves for tumor stage (A) and total tumor dose (B). 
Table 2: Toxicity during this phase I study as scored according to CTCAE v3.0

\begin{tabular}{|c|c|c|c|c|c|}
\hline Toxicity, n & Grade 0 & Grade 1 & Grade 2 & Grade 3 & Grade 4 \\
\hline Asthenia & 13 & 17 & 10 & 0 & 0 \\
\hline Vomiting & 9 & 16 & 12 & 3 & 0 \\
\hline \multirow{3}{*}{$\begin{array}{l}\text { Esophagitis } \\
\text { Acute } \\
\text { Chronic }\end{array}$} & & & & & \\
\hline & 23 & 8 & 9 & 0 & 0 \\
\hline & 29 & 7 & 4 & 0 & 0 \\
\hline Diarrhea & 36 & 4 & 0 & 0 & 0 \\
\hline Skin & 15 & 25 & 0 & 0 & 0 \\
\hline \multirow{3}{*}{$\begin{array}{l}\text { Lung } \\
\text { Acute } \\
\text { Chronic }\end{array}$} & & & & & \\
\hline & 20 & 10 & 8 & 2 & 0 \\
\hline & 25 & 8 & 4 & 3 & 0 \\
\hline Weight loss & 9 & 29 & 2 & 0 & 0 \\
\hline Pain & 13 & 8 & 11 & 8 & 0 \\
\hline Hemoptysis & 29 & 10 & 1 & 0 & 0 \\
\hline \multirow{4}{*}{$\begin{array}{l}\text { Hematology } \\
\text { Erythrocyte } \\
\text { Leukocyte } \\
\text { Platelet }\end{array}$} & & & & & \\
\hline & 26 & 9 & 5 & 0 & 0 \\
\hline & 11 & 12 & 11 & 5 & 1 \\
\hline & 25 & 11 & 3 & 0 & 1 \\
\hline
\end{tabular}

Abbreviations: CTCAE $=$ Common Terminology Criteria for Adverse Events, $n=$ number.

Table 3: Univariate and multivariate analysis for OS, PFS and LRFS

\begin{tabular}{|l|c|c|c|c|}
\hline \multicolumn{1}{|c|}{ Factors } & \multicolumn{2}{c|}{ OS } & PFS & LRFS \\
\hline & Univariate & Multivariate & Univariate & Univariate \\
\hline TTD & $0.035^{*}$ & 0.033 & 0.144 & 0.007 \\
\hline Stage & 0.029 & 0.020 & 0.084 & 0.261 \\
\hline Age & 0.529 & NA & 0.980 & 0.684 \\
\hline Pathology & 0.645 & NA & 0.262 & 0.926 \\
\hline V20 & 0.130 & NA & 0.131 & 0.353 \\
\hline Lung perfusion deficit & 0.307 & NA & 0.302 & 0.444 \\
\hline Short-term effects & 0.550 & NA & 0.443 & 0.466 \\
\hline Toxicity & 0.475 & NA & 0.126 & 0.366 \\
\hline SUVmax & 0.280 & NA & 0.624 & 0.417 \\
\hline SUVmean & 0.291 & NA & 0.508 & 0.472 \\
\hline
\end{tabular}

Abbreviations: $\mathrm{OS}=$ overall survival, $\mathrm{PFS}=$ progression free survival, $\mathrm{LRFS}=$ local recurrence free survival, $\mathrm{TTD}=$ total tumor dose, $\mathrm{NA}=$ not analysed, $\mathrm{V} 20=$ volume of the whole lung receiving $\geq 20 \mathrm{~Gy}$, SUVmax $=$ maximal standard uptake value, $\mathrm{SUVmean}=$ mean standard uptake value.

* Result of univariate analysis stratified by stage.

1 patient experienced grade 3 chronic RTP. Patients in the fifth cohort were treated with a mean radiotherapy dose of $71.3 \mathrm{~Gy}$ (95\% CI, 66.7-75.8 Gy), and 2 patients (25.0\%) developed grade 3 acute RTP while 1 patient (12.5\%) developed grade 3 chronic RTP, thus reaching the maximum tolerated value (MTV). Therefore, a V20 equal to $37 \%$ was the MTV according to the study design, and the trial was closed to accrual. Thus, 35\% was recommended as V20 value in isotoxic radiotherapy. Total tumor dose (TTD) was escalated along with the increasing of V20 in the cohorts, especially in the last 2 cohorts. Finally, 19 patients were assigned to the standard dose (SD) group (mean, 59.4 Gy, range, 51.2-65.2 Gy), while 21 patients to the higher dose (HD) one (mean, 71.3 Gy, range, 68.0-79.2 Gy).

\section{Toxicity}

Toxicity of the patients were summarized in Table 2. Most toxicities, including diarrhea, skin problems, weight loss, and hemoptysis were common but mild. Thirty percent of all patients had grade 2 toxicities with asthenia, vomiting, and esophagitis that were rapidly resolved after the start of supportive care, antiemetic therapy, and steroids, respectively. Hematology toxicity was not frequent, but 5 patients with grade 3 and 1 patient with grade 4 hematological toxicities were prescribed granulocyte colony-stimulating factor during treatment. Ten of forty patients $(25.0 \%)$ experienced severe acute toxicity ( $\geq$ grade 3 ) while three patients $(7.5 \%)$ experienced severe late toxicity ( $\geq$ grade 3$)$. No statistically significant difference was found in overall 
Table 4: Fators grouping criteria in Kaplan-Meier method

\begin{tabular}{|l|c|c|c|c|c|}
\hline \multicolumn{1}{|c|}{ Factors } & \multicolumn{4}{c|}{ Assignment instructions } & \\
\hline Tumor stage & III a $=1$ & III $\mathrm{b}=2$ & & & \\
\hline TTD (Gy) & $50-66=1$ & $>66=2$ & & & \\
\hline Age (years) & $\leq 60=1$ & $61-70=2$ & $>70=3$ & & \\
\hline Pathology & SCC $=1$ & AC $=2$ & LCC $=3$ & & $37=5$ \\
\hline V20 (\%) & $27=1$ & $30=2$ & $33=3$ & $35=4$ & $3=3$ \\
\hline LPD (grade) & $0=0$ & $1=1$ & $2=2$ & & \\
\hline Short-term effects & CR+PR $=1$ & SD $=0$ & & & \\
\hline Toxicity & $0-2$ grade $=0$ & $\geq 3$ grade $=1$ & & & \\
\hline SUVmax & $\leq 10=1$ & $>10, \leq 20=2$ & $>20=3$ & & \\
\hline SUVmean & $\leq 4=1$ & $>4, \leq 6=2$ & $>6=3$ & & \\
\hline
\end{tabular}

Abbreviations: $\mathrm{TTD}=$ total tumor dose, $\mathrm{SCC}=$ squamous carcinoma, $\mathrm{AC}=$ adenocarcinoma, $\mathrm{LCC}=$ large cell carcinoma, $\mathrm{V} 20=$ volume of the whole lung receiving $\geq 20 \mathrm{~Gy}, \mathrm{LPD}=$ lung perfusion deficit, $\mathrm{CR}=$ complete response, $\mathrm{PR}=$ partial response, $\mathrm{SD}=$ stable disease, SUVmax= maximal standard uptake value, SUVmean= mean standard uptake value.

severe toxic events ( $\geq$ grade 3 ) between the SD group and HD group ( 4 of 19 patients [21.1\%] vs. 7 of 21 patients $[33.3 \%], P=0.488)$, or in severe pulmonary toxicity between the two groups ( 2 of 19 patients [10.5\%] vs. 3 of 21 patients $[14.3 \%], P=1.00)$.

\section{Tumor response, overall survival, local recurrence free survival and progression free survival}

Among the 40 patients, 7 achieved complete response, 25 partial response, and 8 stable disease after treatment. The overall response rate was $80 \%$. There were no statistically significant differences in response rates between SD and HD groups (84.2\% vs. $76.2 \%, P=0.698)$, IIIa and IIIb groups $(88.2 \%$ vs. $73.9 \%, P=0.428)$.

By the last follow-up of Apr. 2016, follow-up for all patients ranged from 1 to 112 months (median, 22.5 months) with survival patients from 99 to 112 months. Median progression free survival (PFS) was 13.0 months (95\% CI, 10.5-15.5 months; Figure 1A). Twenty-two patients $(55 \%)$ developed recurrence within the target volume, while sixteen $(40 \%)$ patients experienced distant metastases at the following sites: brain (4 patients), lung (5 patients), bone (4 patients), pleura (3 patients), nonregional lymph node (1 patient) and adrenal gland (1 patient). Thirty-six death events had occurred, including 18 in the SD group and 18 in the HD group. They all died of cancer related reasons except one patient died of heart attack. Median OS was 25.0 months (95\% CI, 22.5-27.5 months), with 1-, 3-, 5- and 8-year OS rates of $72.5 \%$, $22.5 \%, 17.5 \%$, and $10.0 \%$, respectively (Figure 1B).

\section{Uni- and multi-variate analysis survival}

On univariate analysis, patients of stage IIIa achieved a longer median OS than those of stage $\mathrm{IIIb}$ (31 vs. 21 months, $P=0.029$; Figure 2A), and there was a trend that patients in HD group achieved a longer median OS than those in SD one (27 vs. 16 months, $P=$ 0.053 ; Figure 2B). There was no significant correlation between stage and TTD in the chi-square test $(P=1.000)$. Noteworthily, in order to eliminate the effects of stage, univariate survival analysis was repeated testing TTD stratified by stage. The result indicated that patients in HD group achieved a significantly longer median OS than those in SD one (stage IIIa, 34 vs. 19 months; stage IIIb, 24 vs. 11 months; $P=0.035$, Figure 3). Local recurrence free survival (LRFS) of HD group was also better than that of SD one (median, 24 vs. 12 months, $P=0.007$; Figure 4). The other factors were not correlated with OS or LRFS, and all factors investigated were not correlated with PFS (Table 3$)$. On multivariate analysis an early stage $(P=$ $0.020)$ and $\operatorname{HD}(P=0.033)$ remained independent factors for a better OS.

\section{DISCUSSION}

The recognition of cancer heterogeneity has driven us away from the 'one size fits all' approach and has allowed tailoring of treatment to individualised patienttumor characteristics. However, the current radiotherapy is still prescribed at fixed doses (typically 60-66 Gy) for all patients with LANSCLC, and the prognosis is unsatisfactory [25]. Many researchers hold the idea that radiation dose escalation might improve local control and OS of patients with stage III NSCLC [26-29], but the accompanying increased radiation-related toxicity has limited its application. In addition, the outcome of the phase III RTOG 0617 trial was disappointing, in which higher radiation dose of 74 Gy did not produce an OS benefit compared with the standard dose of $60 \mathrm{~Gy}$, and greater toxicity was still considered to be the main reason $[10,30]$. Thus, it is essential to achieve an acceptable balance between therapeutic effect and radiation-related toxicity. Many ongoing studies including RTOG 1106 are focused on delivering high dose radiotherapy while limiting normal tissue doses. To our best knowledge, 
this study is the first study on individual isotoxic dose escalation in CCRT for patients with unresectable stage III NSCLC based on V20 with new radiotherapy approaches (including PET-CT, SPECT, shrinking field and LCAHF IMRT), particularly with an over 9 years follow up. Besides, the recommended value of V20 in isotoxic radiotherapy of CCRT for patients with LANSCLC was first reported.

Our results indicated that dose escalation in CCRT for patients with LANSCLC and the protocol we used were feasible. The conclusion of RTOG 0617 might imply that it was not reasonable to give all patients a radiation dose enhancement to a particular dose. Isotoxic radiotherapy,

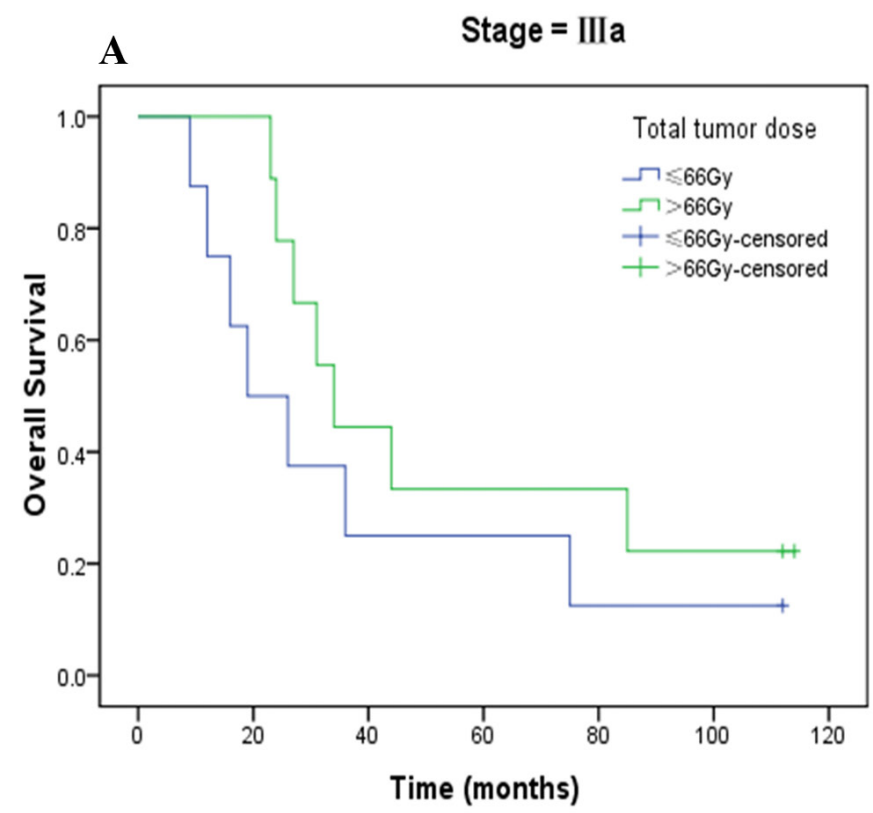

which take into consideration the variability of tumor size/volume, anatomical location, stage and normal tissue constraints, is a novel concept of personalised radiotherapy treatment allowing the individualised administration of radiotherapy dose based on predefined normal tissue constraints. This approach ensures the delivery of the maximum achievable biological equivalent dose for each patient whilst ensuring the safety of the OARs. Van et al reported individualised dose escalation with hyperfractionated accelerated 3D CRT was achievable and associated with mild toxicity in a prospective study of 137 patients with medically inoperable stage III NSCLC treated with CCRT [31]. A median OS of 25.0 months

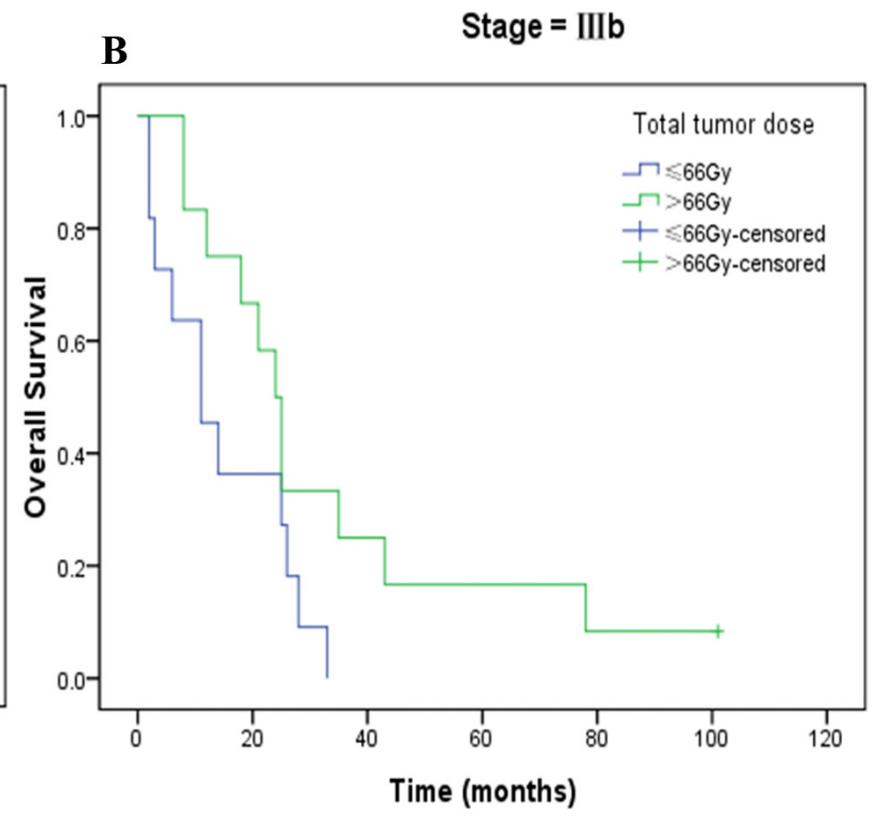

Figure 3: Kaplan-Meier OS curves for total tumor dose stratified by tumor stage (A, stage IIIa; B, stage IIIb).

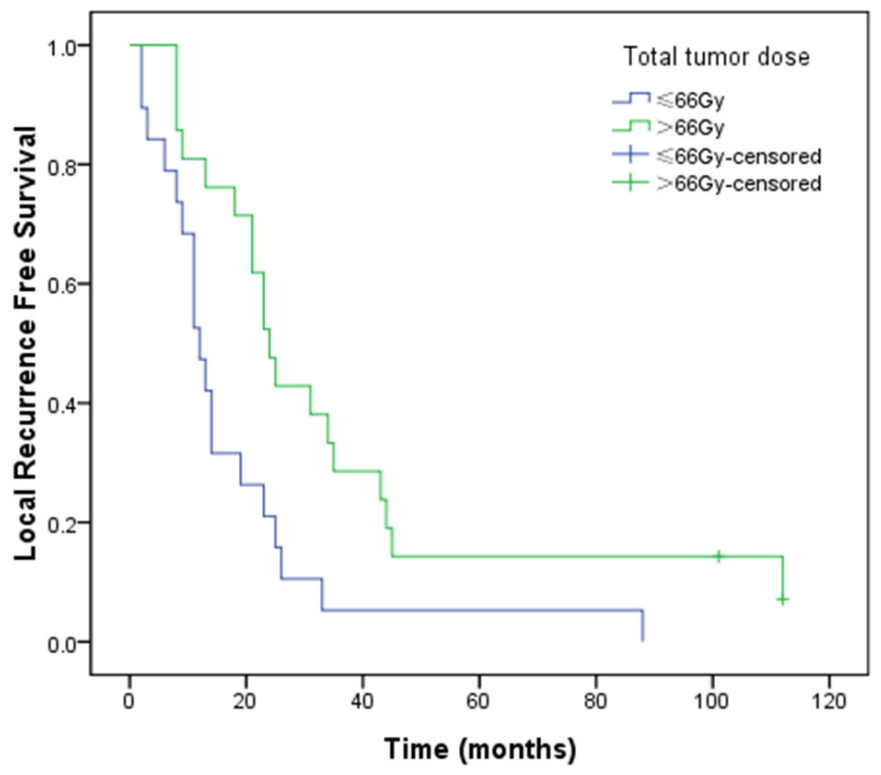

Figure 4: Kaplan-Meier LRFS curves for total tumor dose. 
was reported in their study, which was the same as ours. A median PFS of 14.0 months in their study was slightly longer than that in ours (13.0 months). The incidence of severe acute toxicity ( $\geq$ grade 3 ) in our study $(25.0 \%$ ) was lower than that in theirs $(35.8 \%)$, while the incidences of severe late toxicity ( $\geq$ grade 3 ) were similar $(7.5 \%$ vs. $7.3 \%$, respectively). Obviously, higher incidences of severe toxicity ( $\geq$ grade 3 ) were reported by RTOG 0617 : $165(76 \%)$ of 217 patients in the standard-dose group and $163(79 \%)$ of 207 in the high-dose group.

The conventional approach could result in the under-treatment of patients who could potentially receive higher doses of radiation. Our research demonstrated that, on the premise of compliance with OARs dose constraints, patients of LANSCLC accepted CCRT with higher TTD had significant OS and LRFS benifits. In our study, the mean TTD was increased from 59.4 Gy in SD to 71.3 Gy in HD, but no statistically significant difference was found in overall severe toxicity $(P=0.488)$, or in severe pulmonary toxicity $(P=1.00)$ between the two groups. Furthermore, it was worth noting that LRFS was better with $\mathrm{HD}$ than $\mathrm{SD}(P=0.007)$, and $\mathrm{OS}$ was found to be better with HD and an early stage. Otherwise, no significant correlation was found between stage and TTD $(P=1.000)$. We concluded that dose escalation improved LRFS rates, further to OS rates. Our results agreed with those of previous studies, in which improved survival was achieved in patients who received higher total dose with acceptable toxic effects $[32,33]$. The median OS of HD group in our research (27.0 months) was longer than that of high-dose group (20.3 months) in RTOG 0617, but slightly shorter than that of standard-dose group (28.7 months) in the same trial, one possible reason was the potential improvements in clinical care. The median OS of SD group in our study (16.0 months) was shorter than that of standard-dose group (28.7 months) in RTOG 0617, apart from the small sample size, the under-treatment of patients might be another reason [34]. Patients of stage III NSCLC were variable because of the small sample size, optimal dose margins could not be found for patients of different subgroups. Whether there were optimal dose margins in isotoxic radiotherapy for different patients subgroups need further clinical trials.

New approaches played a critical role in our research. Advanced technologies including PET-CT, SPECT lung perfusion and IMRT were used. Firstly, several studies [35-38] on the impact of PET on treatment planning for NSCLC suggested an overall improvement in target volume delineation. Radiotherapy adaptive to tumor shrinkage determined by repeated PET-CT after 40 Gy during treatment course might be feasible to spare more normal tissues [22]. Secondly, results have demonstrated that, incorporation of SPECT functional information into conformal radiotherapy planning can allow reduction $3 \%-17 \%$ in the volume of the bilateral functional lung (FL) receiving $\geq 20 \mathrm{~Gy}$, and particularly, where discrete nonfunctional regions of significant size are detected [17, 19]. Thirdly, hyperfractionated and/ or accelerated radiotherapy showed an absolute 5-year survival benefit of $2.5 \%$ over conventional fractionation [39]. Fourthly, the combination of SPECT imaging data with IMRT techniques had shown the potential to improve FL avoidance when compared to SPECT-based conformal plans [20].

$\mathrm{V} 20$ is commonly used as a predictor of radiation pneumonitis. To date, very few studies have investigated the MTV in treatment regimens with concomitant chemotherapy and isotoxic radiotherapy. In this study, we concluded that, for patients meet the enrolled criteria, $37 \%$ was the MTV in this treatment regimen and we recommended $35 \%$ as the appropriate value for V20 in isotoxic radiotherapy with the help of PET-CT and SPECT.

There are several limitations in this study. Firstly, the relatively small sample size is liable to compromise the generalizability of the findings. Secondly, patient selection is unavoidable in single-institution studies. Thus, larger prospective multicenter studies are necessary. Thirdly, the fact that the efficacy of pemetrexed in CCRT is superior in patients with nonsquamous histology was not known when the study was designed, and all patients accepted the same chemotherapy regimen consisted of vinorelbine and cisplatin. Univariate analysis showed no difference in survival among patients with different pathology (Table 3).

In conclusion, long-term outcomes of our study indicate that individual isotoxic dose-escalated CCRT in unresectable stage III NSCLC patients based on V20 and new radiotherapy approaches is feasible and effective. In the future, the radiation dose escalation for these patients should be focused on toxicity control and advanced technology application.

\section{MATERIALS AND METHODS}

\section{Patients}

Consecutive patients treated at our institution from March 2006 to May 2009 were enrolled for this study. The eligibility criteria were as follows: histologically and/ or cytologically diagnosed unresectable stage IIIa or IIIb NSCLC with measurable lesions (according to the cancer staging manual sixth edition of American Joint Committee on Cancer); age of 18 years or older; Eastern Cooperative Oncology Group (ECOG) performance status of 0 or 1; weight loss of $10 \%$ or less during the 3 months before the diagnosis; and no history of previous radiotherapy and/or chemotherapy. Patients were also required to undergo brain magnetic resonance imaging (MRI) or CT to rule out asymptomatic brain metastasis at the start of the study. Patients with malignant pleural effusion and/or 
contralateral hilar node involvement were not eligible. All patients underwent PET-CT simulations and SPECT lung perfusion scans in the same treatment position. All patients signed the written informed consent before the treatment.

\section{Dose escalation protocol}

Isotoxic radiotherapy was based on strict normal tissue dose limits, and the dose-volume constraints on OARs used for plan optimization were as follows: esophagus $\mathrm{D}_{\max } \leq 75 \mathrm{~Gy}$, spinal cord $\mathrm{D}_{\max } \leq 50 \mathrm{~Gy}$, heart $\mathrm{V} 65 \leq 33 \%$ (the volume of the whole heart receiving $\geq 65$ Gy) and V45 $\leq 67 \%$, hepatic $\mathrm{V} 35 \leq 50 \%$, and gastric $\mathrm{D}_{\max }$ $\leq 50$ Gy. The maximum tolerated lungs V20 was explored. The acute and chronic toxicity profile of V20 had already been assessed. Patients were divided into cohorts of eight patients in each. Patients with a V20 of $27 \%$ as a base level were entered in the first cohort [40]. From the second cohort, the V20 was further increased to $30 \%, 33 \%, 35 \%$, and $37 \%$, respectively. The criterion for cessation of dose escalation was defined as $25 \%$ of patients or above (i.e., $\geq 2$ patients) experienced dose-limiting toxicities (DLTs). We declared this V20 level as the MTV. DLTs were defined as Grade 3 or 4 RTP and grade 4 RTE, according to the Common Terminology Criteria for Adverse Events (CTCAE) v3.0. Patients with TTD over 66 Gy would be assigned to the HD group, while the others to the $\mathrm{SD}$ one [41]. Estimation algorithm was used to sum up V20 of two phases radiotherapy (details were described below). Total dose for the first phase of the radiotherapy was defined as D1, total dose for the second phase was defined as D2. Plans for two phases (plan 1 and plan 2) were evaluated according to the total dose of D1+D2 by treatment planning system, and V20 of two plans were acquired respectively ( $\mathrm{V} 20^{1}$ and $\mathrm{V} 20^{2}$ ). The final V20 was calculated according to the following formula: V20 $\times \mathrm{D} 1 /$ $(\mathrm{D} 1+\mathrm{D} 2)+\mathrm{V} 20^{2} \times \mathrm{D} 2 /(\mathrm{D} 1+\mathrm{D} 2)$

\section{Treatment}

All patients were assigned to receive concurrent administration of chemotherapy and LCAHF IMRT. In the first phase of the radiotherapy, radiation was administered at a total dose of 40 Gy over a 4-week period, with daily fractions of 2 Gy on consecutive weekdays. In the second phase, hyperfractionation radiotherapy was administered with $1.4 \mathrm{~Gy} /$ fraction, twice daily with a minimum interval of $6 \mathrm{~h}, 10$ fractions a week. The total radiation dose was given individualized according to the normal tissue dose limits and V20 of lungs for each cohort.

The gross target volume (GTV), which encompassed only the radiologically visible tumor, was delineated according to the FDG PET-CT images, and elective nodal radiotherapy was not performed. The GTV was delineated and agreed upon by two radiation oncologists and a radiologist on all CT and PET images. The clinical target volume (CTV) was GTV plus a 5- or 7-mm margin in all directions for squamous cell carcinoma and adenocarcinoma [42], respectively. The planning target volume (PTV) was defined as the CTV plus a 5-mm margin in all directions. For involved lymph nodes, an 8-mm margin was added to achieve the PTV. The heart, spinal cord, and esophagus were delineated by the same radiation oncologists. PET-CT was performed again after 40 Gy to shrink radiation fields, and GTV for late course IMRT was the residual visible disease.

SPECT lung perfusion images were co-registered manually with PET-CT images using the ADAC Pinnacle ${ }^{3}$ version 7.4f planning system (ADAC Inc, CA, USA) and were used to define the FL and nonfunctional lung (NFL). FL refers to the region with $30 \%$ or more maximum radioactive counts, and the residual region was defined as the NFL [43]. Then, SPECT lung perfusion images were classified into 4 grades by comparing SPECT lung perfusion deficits with areas of radiological abnormality: grade 0 referred to no lung perfusion deficit; grade 1 referred to an area of NFL less than the size of 1 pulmonary lobe; grade 3 referred to an area of NFL exceeding the size of 1 lateral lung; and grade 2 was between grades 1 and 3 .

IMRT plans were optimized to minimize the volumes of FL exposed to radiation based on SPECT lung perfusion imaging. During IMRT plans optimizing, beam weights were optimized by minimizing 3 different lung parameters in addition to constraints for the PTV. These lung parameters were the mean functional lung dose, the relative volume of FL receiving $\geq 20 \mathrm{~Gy}$, and the volume of FL receiving $\geq 30 \mathrm{~Gy}$.

Two cycles concurrent chemotherapeutic agents were cisplatin $25 \mathrm{mg} / \mathrm{m}^{2}$ on days 1-3 and vinorelbine 25 $\mathrm{mg} / \mathrm{m}^{2}$ on days 1 and 8 . After completion of concurrent chemotherapy and radiotherapy, an additional 2 cycles of vinorelbine and cisplatin chemotherapy were administered. Patients were allowed to receive full supportive care and symptomatic treatments during radiotherapy.

\section{Follow up, toxicity and response evaluation}

Toxicity evaluations, including those for the hematological system, esophagus, gastrointestinal tract, and pulmonary system, were performed weekly during treatment. Patients were followed up every 2 months during the first 2 years after completion of treatments, every 6 months during years 2-5, and annually over 5 years. Evaluations included physical examination, routine blood work, and thoracic CT scan. Brain MRI and abdomen ultrasound were done every 6 months for the first 2 years, and then once a year. Additional tests were ordered whenever there was any indication from results of examinations. Follow-up time was defined as from the end of the treatment to the patients' death or last follow-up time. Patients were scored for toxicity and evaluated for 
tumor response according to CT scans. Tumor responses were evaluated according to the Response Evaluation Criteria in Solid Tumors (RECIST) [44]. Toxicity was graded according to the CTCAE v3.0. OS was defined as time from diagnosis till death or last follow-up time, and PFS was defined as the time from diagnosis until first clinical event (local or distant progression, death from any cause or last follow-up time).

\section{Statistical design and analysis}

Descriptive statistics were generated for toxicity and response. The Kaplan-Meier method was used for univariate survival analysis (log-rank test) testing the following variables: tumor stage, TTD, age, pathology, lung V20, lung perfusion deficit, short-term effects, toxicity, maximal standard uptake value (SUVmax) and SUVmean. SUVs were abstracted from PET-CT before treatment. Grouping criteria were listed in Table 4. The Cox proportional hazards model was used for multivariate analysis. Comparisons between SD and HD, IIIa and IIIb groups were evaluated using the Chi-square test, Fisher's exact test. All statistical analyses were performed using SPSS 22.0 (IBM Corp, NY, USA). A $P$ value of $<0.05$ was considered significant.

\section{ACKNOWLEDGMENTS}

The authors acknowledge the significant contribution of Ying Feng (University of Florida Health Proton Therapy Institute) in the preparation of this manuscript.

\section{CONFLICTS OF INTEREST}

The authors have declared no conflicts of interest.

\section{GRANT SUPPORT}

This study was supported in part by 81272501 and 81530060 from National Nature Science Foundation of China, and ZR2015QZ09 from Nature Science Foundation of Shandong Province.

\section{REFERENCES}

1. Van den Heuvel MM, Uyterlinde W, Vincent AD, de Jong J, Aerts J, Koppe F, Knegjens J, Codrington H, Kunst PW, Dieleman E, Verheij M, Belderbos J. Additional weekly Cetuximab to concurrent chemoradiotherapy in locally advanced non-small cell lung carcinoma: efficacy and safety outcomes of a randomized, multi-center phase II study investigating. Radiother and Oncol. 2014; 110: 126-131.

2. Yamamoto N, Nakagawa K, Nishimura Y, Tsujino K, Satouchi M, Kudo S, Hida T, Kawahara M, Takeda K,
Katakami N, Sawa T, Yokota S, Seto T, et al. Phase III study comparing second- and third-generation regimens with concurrent thoracic radiotherapy in patients with unresectable stage III non-small-cell lung cancer: West Japan Thoracic Oncology Group WJTOG0105. J Clin Oncol. 2010; 28: 3739-3745.

3. Jalal SI, Riggs HD, Melnyk A, Richards D, Agarwala A, Neubauer M, Ansari R, Govindan R, Bruetman D, Fisher W, Breen T, Johnson CS, Yu M, et al. Updated survival and outcomes for older adults with inoperable stage III nonsmall-cell lung cancer treated with cisplatin, etoposide, and concurrent chest radiation with or without consolidation docetaxel: analysis of a phase III trial from the Hoosier Oncology Group (HOG) and US Oncology. Ann Oncol. 2012; 23: 1730-1738.

4. Belderbos JS, Heemsbergen WD, De Jaeger K, Baas P, Lebesque JV. Final results of a Phase I/II dose escalation trial in non-small-cell lung cancer using three-dimensional conformal radiotherapy. Int J Radiation Oncol. 2006; 66: 126-134.

5. Bradley J. A review of radiation dose escalation trials for non-small cell lung cancer within the Radiation Therapy Oncology Group. Seminars in oncology. 2005; 32: S111-3.

6. Kong FM, Ten Haken RK, Schipper MJ, Sullivan MA, Chen M, Lopez C, Kalemkerian GP, Hayman JA. Highdose radiation improved local tumor control and overall survival in patients with inoperable/unresectable nonsmall-cell lung cancer: long-term results of a radiation dose escalation study. Int J Radiat Oncol. 2005; 63: 324-333.

7. Lee CB, Stinchcombe TE, Rosenman JG, Socinski MA. Therapeutic advances in local-regional therapy for stage III non-small-cell lung cancer: evolving role of dose-escalated conformal (3-dimensional) radiation therapy. Clin Lung Cancer. 2006; 8: 195-202.

8. Socinski MA, Morris DE, Halle JS, Moore DT, Hensing TA, Limentani SA, Fraser R, Tynan M, Mears A, Rivera MP, Detterbeck FC, Rosenman JG. Induction and concurrent chemotherapy with high-dose thoracic conformal radiation therapy in unresectable stage IIIA and IIIB non-small-cell lung cancer: a dose-escalation phase I trial. J Clin Oncol. 2004; 22: 4341-4350.

9. Machtay M, Paulus R, Moughan J, Komaki R, Bradley JE, Choy H, Albain K, Movsas B, Sause WT, Curran WJ. Defining local-regional control and its importance in locally advanced non-small cell lung carcinoma. J Thorac Oncol. 2012; 7: 716-722.

10. Bradley JD, Paulus R, Komaki R, Masters G, Blumenschein G, Schild S, Bogart J, Hu C, Forster K, Magliocco A, Kavadi V, Garces YI, Narayan S, et al. Standard-dose versus high-dose conformal radiotherapy with concurrent and consolidation carboplatin plus paclitaxel with or without cetuximab for patients with stage IIIA or IIIB nonsmall-cell lung cancer (RTOG 0617): a randomised, twoby-two factorial phase 3 study. Lancet Oncol. 2015; 16: 187-199. 
11. Christodoulou M, Bayman N, McCloskey P, Rowbottom C, Faivre-Finn C. New radiotherapy approaches in locally advanced non-small cell lung cancer. Eur J Cancer. 2014; 50: $525-534$.

12. Zindler JD, Thomas CR Jr, Hahn SM, Hoffmann AL, Troost EG, Lambin P. Troost, Philippe Lambin. Increasing the Therapeutic Ratio of Stereotactic Ablative Radiotherapy by Individualized Isotoxic Dose Prescription. J Natl Cancer Inst. 2016; 108: djv305.

13. De Ruysscher D, Nestle U, Jeraj R, Macmanus M. PET scans in radiotherapy planning of lung cancer. Lung Cancer. 2012; 75: 141-145.

14. De Ruysscher D, Belderbos J, Reymen B, van Elmpt W, van Baardwijk A, Wanders R, Hoebers F, Vooijs M, Ollers M, Lambin P. State of the art radiation therapy for lung cancer 2012: a glimpse of the future. Clin Lung Cancer. 2013; 14: 89-95.

15. Christian JA, Bedford JL, Webb S, Brada M. Comparison of inverse-planned three-dimensional conformal radiotherapy and intensity-modulated radiotherapy for non-small-cell lung cancer. Int J Radiat Oncol. 2007; 67: 735-741.

16. Yamamoto T, Kabus S, von Berg J, Lorenz C, Keall PJ. Impact of four-dimensional computed tomography pulmonary ventilation imaging-based functional avoidance for lung cancer radiotherapy. Int J Radiat Oncol. 2011; 79: 279-288.

17. Seppenwoolde Y, Engelsman M, De Jaeger K, Muller SH, Baas P, McShan DL, Fraass BA, Kessler ML, Belderbos JS, Boersma LJ, Lebesque JV. Optimizing radiation treatment plans for lung cancer using lung perfusion information. Radiother Oncol. 2002; 63: 165-177.

18. Shioyama Y, Jang SY, Liu HH, Guerrero T, Wang X, Gayed IW, Erwin WD, Liao Z, Chang JY, Jeter M, Yaremko BP, Borghero YO, Cox JD, et al. Preserving functional lung using perfusion imaging and intensity-modulated radiation therapy for advanced-stage non-small cell lung cancer. Int J Radiat Oncol. 2007; 68: 1349-1358.

19. Christian JA, Partridge M, Nioutsikou E, Cook G, McNair HA, Cronin B, Courbon F, Bedford JL, Brada M. The incorporation of SPECT functional lung imaging into inverse radiotherapy planning for non-small cell lung cancer. Radiother Oncol. 2005; 77: 271-277.

20. Lavrenkov K, Christian JA, Partridge M, Niotsikou E, Cook G, Parker M, Bedford JL, Brada M. A potential to reduce pulmonary toxicity: the use of perfusion SPECT with IMRT for functional lung avoidance in radiotherapy of non-small cell lung cancer. Radiother Oncol. 2007; 83: 156-162.

21. McGuire SM, Zhou S, Marks LB, Dewhirst M, Yin FF, Das SK. A methodology for using SPECT to reduce intensitymodulated radiation therapy (IMRT) dose to functioning lung. Int J Radiat Oncol. 2006; 66: 1543-1552.

22. Ding XP, Zhang J, Li BS, Li HS, Wang ZT, Yi Y, Sun HF, Wang DQ. Feasibility of Shrinking Field Radiation Therapy through 18F-FDG PET/CT after 40 Gy for Stage III Non-
Small Cell Lung Cancers. Asian Pac J Cancer Prev. 2012; 13: 319-323.

23. Saunders M, Dische S, Barrett A, Harvey A, Gibson D, Parmar M. Continuous hyperfractionated accelerated radiotherapy (CHART) versus conventional radiotherapy in non-small-cell lung cancer: a randomised multicentre trial. CHART Steering Committee. Lancet. 1997; 350: 161-165.

24. Baumann M, Herrmann T, Koch R, Matthiessen W, Appold S, Wahlers B, Kepka L, Marschke G, Feltl D, Fietkau R, Budach V, Dunst J, Dziadziuszko R, et al. Final results of the randomized phase III CHARTWEL-trial (ARO 97-1) comparing hyperfractionated-accelerated versus conventionally fractionated radiotherapy in non-small cell lung cancer (NSCLC). Radiother Oncol. 2011; 100: 76-85.

25. Walters S, Maringe C, Coleman MP, Peake MD, Butler J, Young N, Bergstrom S, Hanna L, Jakobsen E, Kolbeck K, Sundstrom S, Engholm G, Gavin A, et al. Lung cancer survival and stage at diagnosis in Australia, Canada, Denmark, Norway, Sweden and the UK: a population-based study, 2004-2007. Thorax. 2013; 68: 551-564.

26. Kupelian PA, Komaki R, Allen P. Prognostic factors in the treatment of node-negative nonsmall cell lung carcinoma with radiotherapy alone. Int J Radiat Oncol. 1996; 36: $607-$ 613.

27. Willner J, Baier K, Caragiani E, Tschammler A, Flentje $\mathrm{M}$. Dose, volume, and tumor control prediction in primary radiotherapy of non-small-cell lung cancer. Int $\mathrm{J}$ Radiat Oncol. 2002; 52: 382-389.

28. Bradley JD, Ieumwananonthachai N, Purdy JA, Wasserman TH, Lockett MA, Graham MV, Perez CA. Gross tumor volume, critical prognostic factor in patients treated with three-dimensional conformal radiation therapy for nonsmall-cell lung carcinoma. Int J Radiat Oncol. 2002; 52: 49-57.

29. Rengan R, Rosenzweig KE, Venkatraman E, Koutcher LA, Fox JL, Nayak R, Amols H, Yorke E, Jackson A, Ling $\mathrm{CC}$, Leibel SA. Improved local control with higher doses of radiation in large-volume stage III non-small-cell lung cancer. Int J Radiat Oncol. 2004; 60: 741-747.

30. Cox JD. Are the results of RTOG 0617 mysterious? Int J Radiat Oncol. 2012; 82: 1042-1044.

31. Van Baardwijk A, Reymen B, Wanders S, Borger J, Ollers M, Dingemans AM, Bootsma G, Geraedts W, Pitz C, Lunde R, Peters F, Lambin P, De Ruysscher D. Mature results of a phase II trial on individualised accelerated radiotherapy based on normal tissue constraints in concurrent chemoradiation for stage III non-small cell lung cancer. Eur J Cancer. 2012; 48: 2339-2346.

32. Rosenzweig KE, Fox JL, Yorke E, Amols H, Jackson A, Rusch V, Kris MG, Ling CC, Leibel SA. Results of a phase I dose-escalation study using three-dimensional conformal radiotherapy in the treatment of inoperable nonsmall cell lung carcinoma. Cancer. 2005; 103: 2118-2127.

33. Cox JD, Azarnia N, Byhardt RW, Shin KH, Emami B, 
Pajak TF. A randomized phase I/II trial of hyperfractionated radiation therapy with total doses of $60.0 \mathrm{~Gy}$ to $79.2 \mathrm{~Gy}$ : possible survival benefit with greater than or equal to 69.6 Gy in favorable patients with Radiation Therapy Oncology Group stage III non-small-cell lung carcinoma: report of Radiation Therapy Oncology Group 83-11. J Clin Oncol. 1990; 8: 1543-1555.

34. Perez CA, Pajak TF, Rubin P, Simpson JR, Mohiuddin M, Brady LW, Perez-Tamayo R, Rotman M. Long-term observations of the patterns of failure in patients with unresectable non-oat cell carcinoma of the lung treated with definitive radiotherapy. Report by the Radiation Therapy Oncology Group. Cancer. 1987; 59: 1874-1881.

35. Giraud P, Grahek D, Montravers F, Carette MF, DeniaudAlexandre E, Julia F, Rosenwald JC, Cosset JM, Talbot JN, Housset M, Touboul E. CT and (18)F-deoxyglucose (FDG) image fusion for optimization of conformal radiotherapy of lung cancers. Int J Radiat Oncol. 2001; 49: 1249-1257.

36. Deniaud-Alexandre E, Touboul E, Lerouge D, Grahek D, Foulquier JN, Petegnief Y, Gres B, El Balaa H, Keraudy K, Kerrou K, Montravers F, Milleron B, Lebeau B, et al. Impact of computed tomography and 18F-deoxyglucose coincidence detection emission tomography image fusion for optimization of conformal radiotherapy in non-smallcell lung cancer. Int J Radiat Oncol. 2005; 63: 1432-1441.

37. Vanuytsel LJ, Vansteenkiste JF, Stroobants SG, De Leyn PR, De Wever W, Verbeken EK, Gatti GG, Huyskens DP, Kutcher GJ. The impact of (18)F-fluoro-2-deoxy-D-glucose positron emission tomography (FDG-PET) lymph node staging on the radiation treatment volumes in patients with non-small cell lung cancer. Radiother Oncol. 2000; 55: 317 324.

38. De Ruysscher D, Wanders S, Minken A, Lumens A, Schiffelers J, Stultiens C, Halders S, Boersma L, Baardwijk Av, Verschueren T, Hochstenbag M, Snoep G, Wouters $\mathrm{B}$, et al. Effects of radiotherapy planning with a dedicated combined PET-CT-simulator of patients with non-small cell lung cancer on dose limiting normal tissues and radiation dose-escalation: a planning study. Radiother Oncol. 2005; 77: 5-10

39. Mauguen A, Le Pe'choux C, Saunders MI, Schild SE,
Turrisi AT, Baumann M, Sause WT, Ball D, Belani CP, Bonner JA, Zajusz A, Dahlberg SE, Nankivell M, et al. Hyperfractionated or accelerated radiotherapy in lung cancer: an individual patient data meta-analysis. J Clin Oncol. 2012; 30: 2788-2797.

40. Tsujino K, Hirota S, Endo M, Obayashi K, Kotani Y, Satouchi M, Kado T, Takada Y. Predictive value of dosevolume histogram parameters for predicting radiation pneumonitis after concurrent chemoradiation for lung cancer. Int J Radiat Oncol. 2003; 55: 110-115.

41. Hensing T, Halle J, Socinski MA: Chemoradiotherapy for stage IIIA, B non-small cell lung cancer. In: Detterbeck FC, Rivera MP, Socinski MA, Rosenman JG, Editors. Diagnosis and Treatment of Lung Cancer: An Evidence-Based Guide for the Practicing Clinician. Philadelphia, Pa: WB Saunders; 2001. pp 291-303.

42. Giraud P, Antoine M, Larrouy A, Milleron B, Callard P, De Rycke Y, Carette MF, Rosenwald JC, Cosset JM, Housset M, Touboul E. Evaluation of microscopic tumor extension in non-small-cell lung cancer for three-dimensional conformal radiotherapy planning. Int J Radiat Oncol. 2000; 48: 1015-1024.

43. Seppenwoolde Y, Muller SH, Theuws JC, Baas $\mathrm{P}$, Belderbos JS, Boersma LJ, Lebesque JV. Radiation doseeffect relations and local recovery in perfusion for patients with non-small-cell lung cancer. Int J Radiat Oncol. 2000; 47: 681-690.

44. Therasse P, Arbuck SG, Eisenhauer EA, Wanders J, Kaplan RS, Rubinstein L, Verweij J, Van Glabbeke M, van Oosterom AT, Christian MC, Gwyther SG. New guidelines to evaluate the response to treatment in solid tumors. European Organization for Research and Treatment of Cancer, National Cancer Institute of the United States, National Cancer Institute of Canada. J Natl Cancer I. 2000; 92: 205-216. 